\title{
Anatomical Evaluation of The Major Vessels with Ultrasound in Children Undergoing Cardiac Surgery
}

\section{Kardiyak Cerrahi Geçiren Çocuklarda Majör Damarların Ultrason ile Anatomik Olarak Değerlendirilmesi}

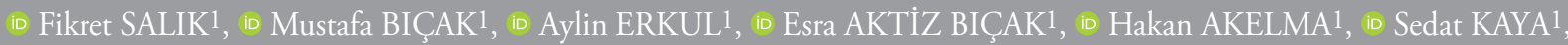

(D) Onur DOYURGAN2, id Cem Kivilcım KAÇAR ${ }^{1}$

${ }^{1}$ University of Health Sciences Turkey Diyarbakır Gazi Yaşargil Training and Research Hospital, Clinic of Anesthesiology and Reanimation,

Diyarbakır, Turkey

2University of Health Sciences Turkey Diyarbakır Gazi Yaşargil Training and Research Hospital, Clinic of Pediatric Cardiovascular Surgery,

Diyarbakır, Turkey

\section{ABSTRACT}

Objective: The aim of this study was to evaluate anatomically bilateral internal jugular veins (IJVs), carotid arteries (CAs), femoral veins (FVs) and femoral arteries (FAs) in pediatric patients undergoing cardiac surgery using ultrasonography (USG) guidance.

Methods: A retrospective study was conducted involving 78 patients. The patients were divided into five different categories (0-1, 1-6, 6-12, 12-24 months and $>24$ months). The diameter $(\mathrm{Dm})$ and depth (Dp) of the bilateral IJVs, CAs, FVs and FAs were measured with USG. The anatomical positions of the IJV, CA, FV and FA and variations were evaluated. The correlations of the Dm and $\mathrm{Dp}$ of the major vessels with age, height, weight, body surface area (BSA), and body mass index were analyzed.

Results: The Dms and Dps of IJV, CA, FV and FA were significantly different between the groups. The rate of anatomical variation was $23.1 \%$ in the right IJV, $28.2 \%$ in the left IJV, $19.2 \%$ in the right FV, and $28.2 \%$ in the left FV. The Dms and Dps of the major central vessels were significantly correlated with age, height, weight, and BSA. The regression coefficient indicated that the 1 year age increase was associated with an increase of $0.414 \mathrm{~mm}$ in the right IJV (RIV) Dm. And each $1 \mathrm{~kg}$ increase in weight was associated with an increase of $0.169 \mathrm{~mm}$ in the RIV Dm.

Conclusion: We found a high correlation between vascular Dms and age, weight, height, and BSA in children with congenital

\section{ÖZ}

Amaç: Bu çalışmada kalp cerrahisi geçiren pediatrik hastalarda ultrasonografi (USG) rehberliği ile bilateral internal juguler ven (IJV), karotis arter (CA), femoral ven (FV) ve femoral arterin (FA) anatomik olarak değerlendirilmesi amaçlanmıştır.

Yöntemler: Yetmiş sekiz hastayı içeren retrospektif bir çalışma dizayn edildi. Hastalar beş farklı yaş kategorisine ayrıldı (0-1 ay, 1-6 ay, 6-12 ay, 12-24 ay ve $>24$ ay). USG ile bilateral IJV, CA, FV ve FA çap $(D m)$ ve derinlikleri $(D p)$ ölçüldü. IJV, CA, FV ve FA'nın anatomik pozisyonları ve varyasyonları değerlendirildi. Majör damarların Dm ve Dp’si ile yaş, boy, ağıllık, vücut yüzey alanı (VYA) ve vücut kitle indeksi arasındaki korelasyonu analiz edildi.

Bulgular: IJV, CA, FV ve FA Dm'si ve Dp'si gruplar arasında anlamlı farkllık gösterdi. Anatomik varyasyon sağ İV'de \%23,1, sol İJV'de $\% 28,2$, sağ FV'de \%19,2 ve sol FV'de \%28,2 idi. Majör damarların Dm’si ve Dp’si yaş, boy, ağırlık ve VYA ile anlamlı derecede korele idi. Regresyon katsayısı, 1 yıllık yaş artışının sağ İJV Dm’sindeki 0,414 mm'lik bir artışla ve ağırlıktaki her 1 kg'lik artı̧ıı sağ İJV Dm’sindeki 0,169 mm'lik bir artışla ilişkili olduğunu gösterdi.

Sonuç: Konjenital kalp hastalı̆̆ı olan çocuklarda vasküler Dm’ler ile yaş, ağırlık, boy ve VYA arasında yüksek bir korelasyon bulduk. Kardiyak cerrahi geçirecek pediyatrik hastalarda kateter girişimlerinden önce uygun damar ve kateter boyutunu belirlemek için majör damarların USG ile değerlendirilmelidir.
Address for Correspondence: Fikret SALIK, University of Health Sciences Turkey Diyarbakır Gazi Yaşargil Training and Research Hospital, Clinic of Anesthesiology and Reanimation, Diyarbakır, Turkey E-mail: fikretsalik@gmail.com ORCID ID: orcid.org/0000-0002-7715-3545
Received: 22.12 .2020

Accepted: 16.02 .2021

Cite this article as: Salık F, Bıçak M, Erkul A, Aktiz Bıçak E, Akelma H, Kaya S, Doyurgan O, Kaçar CK. Anatomical Evaluation of The Major Vessels with Ultrasound in Children Undergoing Cardiac Surgery. Bezmialem Science 2022;10(2):174-83 
heart disease. Major vessels should be evaluated by using USG to determine the appropriate vessel and catheter size before catheter interventions in pediatric patients undergoing cardiac surgery.

Keywords: İnternal jugular vein, femoral vein, femoral artery, correlation, ultrasound
Anahtar Sözcükler: İnternal juguler ven, femoral ven, femoral arter, korelasyon, ultrason

\section{Introduction}

In pediatric cardiac surgery, central venous cannulation (CVC) is mandatory for fluid-blood replacement, inotropic drug support, drug administration, and central venous pressure monitoring, just as arterial cannulation (AC) is also mandatory for continuous arterial pressure monitoring and frequent arterial blood sampling (1). Although the bilateral internal jugular veins (IJVs), subclavian veins (SVs), and femoral veins (FVs) are used for $\mathrm{CVC}$, the radial artery and femoral artery (FA) are more frequently used for AC (2-4).

In most clinics, cannulation attempts are still performed using the anatomical landmark method. However, in pediatric patients, especially those with congenital heart disease, cannulation is difficult because of the diameter $(\mathrm{Dm})$ of the small vessels, difficulty in finding the puncture vessel, and anatomical variations (3). With the increase in the use of ultrasound (USG), the success of CVC and AC administrations has increased and processing time and hospital costs have decreased (4-7). Another advantage of using USG is that it allows for anatomical examination before the intervention to determine the Dm and variations of the major vessels, to select the appropriate size catheter, and to apply cannulation in the correct localization (8). Some studies have also emphasized the correlation between vascular Dm and catheter size in terms of development of thrombosis, and researchers have emphasized that it is important to determine the appropriate catheter size for the vessel Dm using USG for anatomical evaluation before the intervention (9). In addition, USG reduces complication rates such as hematoma, arterial puncture, and pneumothorax in pediatric CVS, which is one of the most risky surgeries, by allowing fewer interventions and optimal vessel selection (10-12). It is a known fact that as the age of children decreases, the Dm of the vessels also shrinks. Thus, the area of the operation is narrower, and the cannulation procedures become more difficult, resulting in an increase in complication rates (13).

The Dm of the central arteries/veins and the anatomical relationships of these vessels may vary in pediatric patients undergoing cardiac surgery. This situation makes catheter administrations more difficult than in healthy patients and requires more experience and effort during administration. Therefore, the use of USG during CVC and/or AC administrations has become more important because of the possibility of anatomical variation, thrombosis, and bleeding in pediatric cardiac surgery patients, who are already at high risk.

In this study, we aim to evaluate anatomically the bilateral IJVs, carotid artery (CAs), FVs, and FAs in pediatric patients undergoing cardiac surgery using USG guidance and to determine the benefit of the findings in establishing the puncture vessel, needle length, and catheter Dm. Simultaneously, this study examines the correlation of the Dm and depth (Dp) of the major vessels with age, height, weight, body surface area (BSA), and body mass index (BMI).

\section{Methods}

\section{Patients}

This retrospective, observational, and descriptive study was conducted at local ethics committee of the hospital. The study was conducted after obtaining approval of the local ethics committee and in accordance with the principles of the Helsinki Declaration. Seventy-eight pediatric patients who underwent cardiac surgery between 01 January 2019 and 01 January 2020 and who underwent central venous catheter and/or FA catheter with USG were included in the study. Patients were divided into five different age categories (0-1 months, 1-6 months, 6-12 months, 12-24 months, and >24 months) to obtain measurements representing the general population. Written consent was obtained from the parents of the patients. Emergency patients, those with a history of operation or cannulation in the jugular or femoral region, and those allergic to the USG gel were excluded from the study. In addition, one patient whose right FA could not be visualized was excluded.

The demographic and clinical characteristics of patients, including age, gender, height, body weight, diagnosis, and presence of additional diseases, were recorded from medical records and observation forms. BSA was calculated in square meters $\left(\mathrm{m}^{2}\right)$ using the Mosteller formula: BSA: [height $(\mathrm{cm}) \mathrm{x}$ weight $(\mathrm{kg}) / 3,600]^{1 / 2}(14)$. The BMI values of the patients were also calculated.

\section{Measurements}

In our clinic, most catheter administrations in pediatric cardiac surgery are performed using anatomical evaluation of large veins and arteries accompanied by USG and selection of the appropriate vessels after detection of any variations. For this purpose, in our clinic, the bilateral IJVs, CAs, FVs, and FAs of each patient are routinely evaluated. Patients' USG data and other parameters are recorded in the files.

After a 4 or 6-hour fasting period, patients were taken to the operation room, and standard anesthesia monitoring was performed. During the preoperative fasting period, the patients were given maintenance intravenous fluid according to the Holiday and Segar formula. The standard anesthesia regimen 
consisted of general anesthesia. For induction, $0.1 \mathrm{mg} / \mathrm{kg}$ midazolam, 2-3 mg/kg propofol, $1-2 \mu \mathrm{g} / \mathrm{kg}$ fentanyl, and 0.6 $\mathrm{mg} / \mathrm{kg}$ rocuronium were applied. After orotracheal intubation, mechanical ventilation was initiated without the use of positive end-expiratory pressure.

For all measurements, we used a USG device (Esaote, MyLab Six, the Netherlands) with a linear probe (5-12 MHz). IJV and CA measurements were obtained with patients in the supine position and after the head was turned about $15^{\circ}$ to the opposite side. The practitioner placed the linear probe at the level of the cricoid cartilage with minimal compression to the neck. We performed the scan by visualizing the IJV on the short axis in the middle of the neck as suggested by the RaCeVA protocol (8). The Dm of the anteroposterior vessels and Dp of the IJV were measured on the short axis and recorded (Figure 1). The anatomical positions

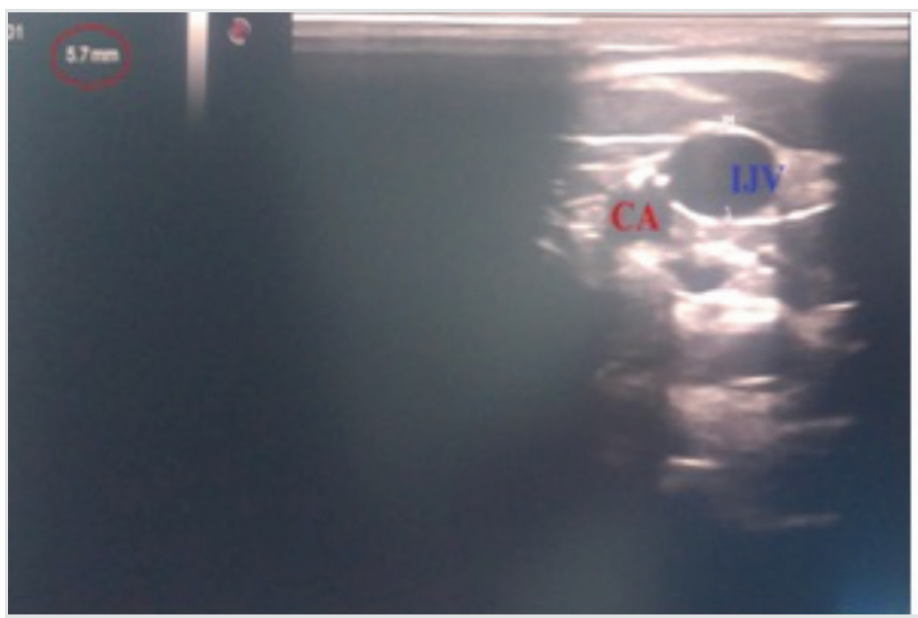

of the IJV and CA relative to each other (eight quadrants: anterior, posterior, medial, lateral, anteromedial, anterolateral, posteromedial, and posterolateral) and variations were evaluated and recorded bilaterally (Figure 2).

The FA-FV Dm and FA Dp were measured with the patients in the supine position and the thigh abducted at approximately $30^{\circ}$. The linear probe was placed with minimal compression on the FA pulsation $1 \mathrm{~cm}$ below the inguinal ligament. While the practitioner was on the side of the patient, the Dm of the anteroposterior vessels and FA Dp were measured on the short axis and recorded (Figure 3). The anatomical positions of the FA and FV relative to each other (possible eight quadrants: anterior, posterior, medial, lateral, anteromedial, anterolateral, posteromedial, and posterolateral) and variations were evaluated bilaterally and recorded (Figure 4).

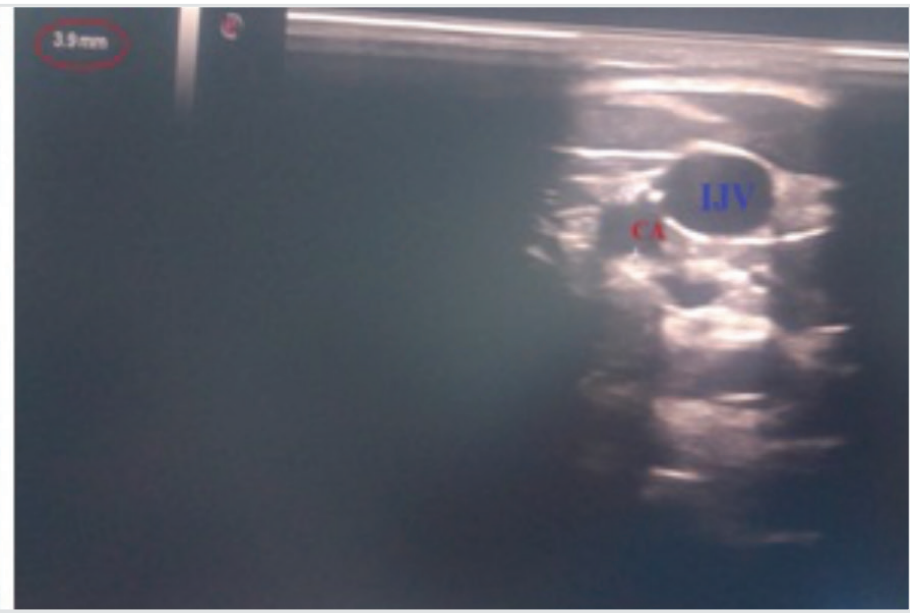

Figure 1. Vascular diameter measurements of the right IJV and CA in a 7-month-old boy IJV: Right internal jugular vein, CA: Carotid artery
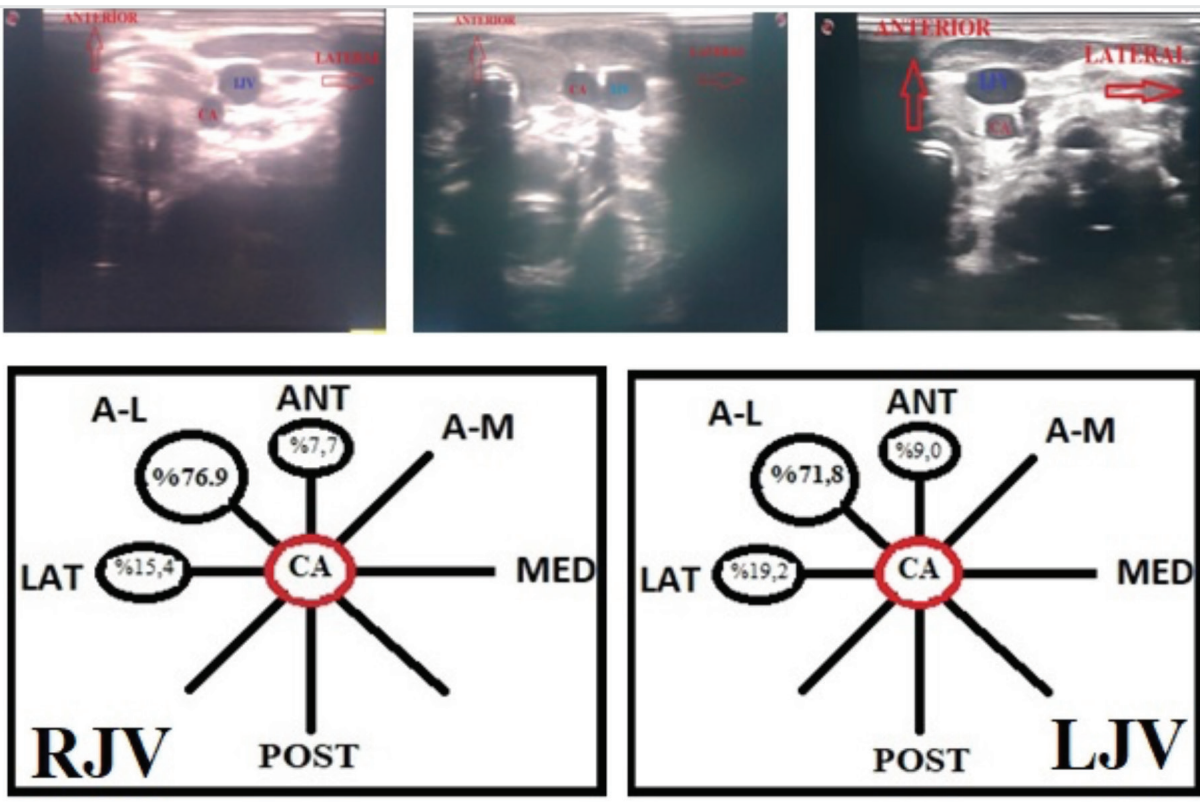

Figure 2. Anatomical variations of the IJV and CA IJV: Right internal jugular vein, CA: Carotid artery 


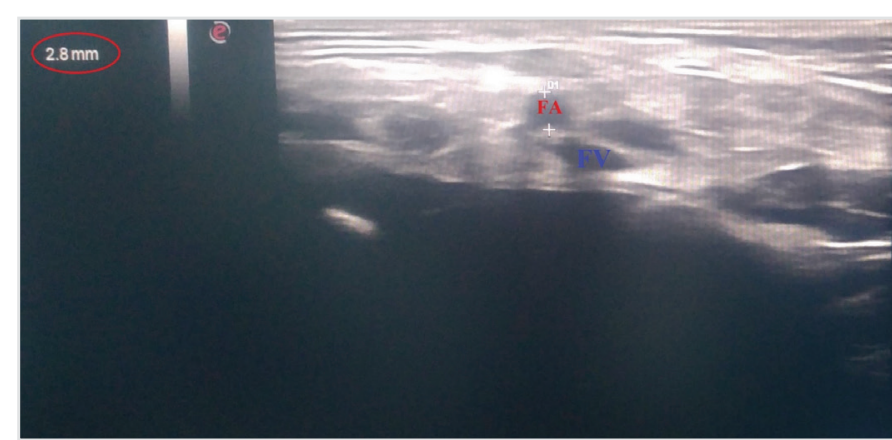

Figure 3. Vascular diameter measurements of the right $\mathrm{FA}$ and $\mathrm{FV}$ in a 17-month-old boy

FA: Femoral artery, FV: Femoral vein

The inner Dm of all vessels were measured anteroposteriorly using a caliper. For Dp, the distance from the skin surface to the anterior wall of the vessel was measured in millimeters. All measurements were performed by two anesthesiologists with USG training and at least 5 years of experience in USG use for interventional procedures and with continuous experience in pediatric CVS. After sterilization conditions were confirmed, the central venous catheter and/or FA catheter was inserted with USG by determining the appropriate vessel. The dimensions of the administered catheters were recorded.

\section{Statistical Analysis}

The SPSS 22.0 for Windows (SPSS Inc., Chicago, IL, USA) was used for statistical analysis. All measurements were expressed
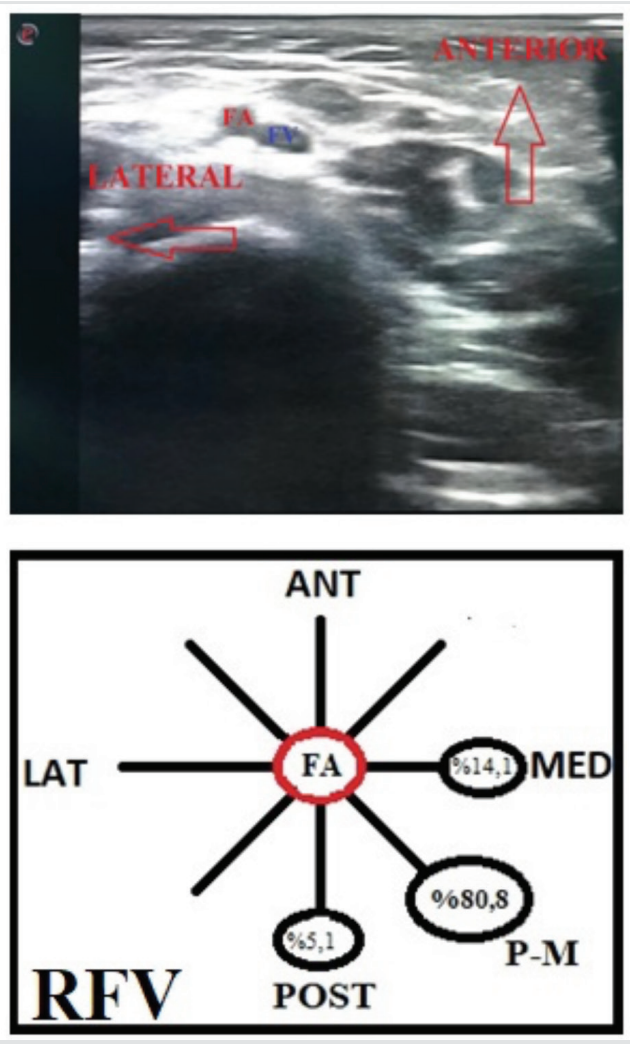

Figure 4. Anatomical variations of the FA and FV

FA: Femoral artery, FV: Femoral vein

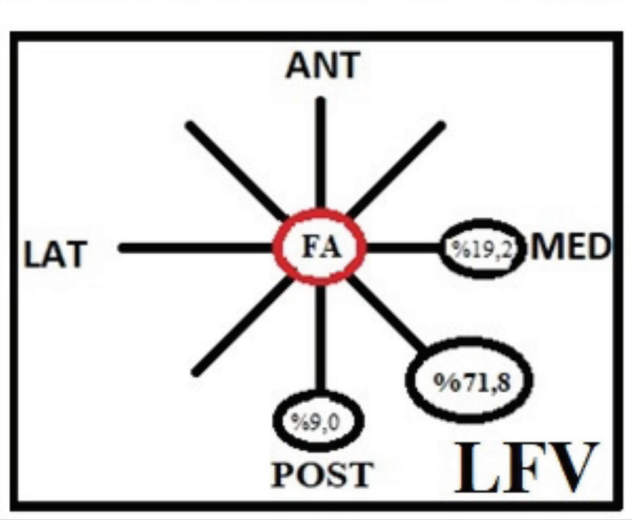

in millimeters. Statistical data were expressed as mean and standard deviation, and categorical data were expressed as frequency and percentage. Categorical data in the groups were compared using chi-square test; the results were given as percentage (n). Pearson chi-square test was used to compare the difference between right and left sides. Kolmogorov-Smirnov test was used to determine whether the numerical data fit the normal distribution. Although the data matching the normality distribution were evaluated using one-way analysis of variance, the Kruskal-Wallis test was used to compare the data that did not conform to the normal distribution. In all comparisons, $\mathrm{p}<0.05$ was considered significant. The relationship between the Dms of bilateral IJVs and FAs, the most frequently used central vessels, and the age was tested with separate, simple linear regressions. Correlation evaluations of normally distributed numerical data were performed by Pearson correlation test, whereas numerical data that did not fit the normal distribution were evaluated by Spearman correlation test. Correlation coefficient $(r)$ results were interpreted as follows:

- $\mathrm{R}<0.2$, weak correlation or no correlation

- $\mathrm{R}=0.2-0.4$, weak correlation

- $\mathrm{R}=0.4-0.6$, moderate correlation

- $\mathrm{R}=0.6-0.8$, high correlation

- $\mathrm{R}>0.8$, very high correlation

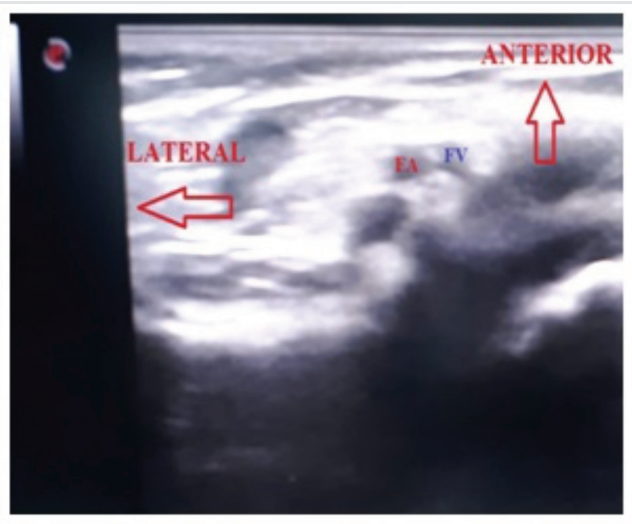




\section{Results}

Seventy-eight patients were included in the study. The patients were divided into five groups based on age: $0-1$ months $(n=15)$, 1-6 months $(n=14), 6-12$ months $(n=22), 12-24$ months $(n=13)$, and $>24$ months $(n=14)$. Table 1 shows the demographic and clinical features of the patients.

Table 2 displays the internal Dm and distance to the skin of the vessels examined anatomically by USG. A statistically significant difference was found between the groups in all measurements. By including all patients $(n=78)$, when the right and left measurements were compared, there was no statistically significant difference between the mean Dm ( $\mathrm{p}$ values were 0.751 for IJV, 0.480 for CA, 0.793 for FV, and 0.720 for FA).

In the analysis that included all measurements, the rate of anatomical variation observed in patients was $25.6 \%$ in IJV and $23.7 \%$ in FV. These rates were $23.1 \%$ in the right IJV, $28.2 \%$ in the left IJV, $19.2 \%$ in the right FV, and $28.2 \%$ in the left FV. Table 3 displays the anatomical variations of the vessels examined with USG. When all measurements were included $(n=78)$, there was no statistically significant difference in the right and left anatomic positions ( $\mathrm{p}=0.461$ for IJV-CA, $\mathrm{p}=0.207$ for FV-FA). In addition, the right FA could not be visualized in one patient, who was excluded from the study.

\section{Correlation}

After demographic data and measurements were analyzed, correlations were determined to estimate the Dm and Dp of the vessels. The Dm and Dp of the major central vessels were significantly associated with age, height, weight, and BSA $(\mathrm{p}<0.001)$. There was no statistically significant relationship between the right and left FA Dp and BMI ( $\mathrm{p}=0.078,0.102$, respectively).

A high or very high correlation was detected between the vessel Dm and age, height, weight, and BSA. Moderate correlations were detected between vascular Dp, age, height, weight, and BSA. A moderate correlation was detected between the Dm of the vessels and the BMI, and a weak correlation was found between the Dp of the vessels and BMI. The highest correlation coefficient values were between the vessel $\mathrm{Dm}$ and height. Pearson $R$ correlation coefficients are shown in Table 4.

\section{Regression}

Separate simple linear regressions were performed to evaluate the relationships between the IJV, CA, FV, and FA Dm and Dp, and age, height, weight, BSA, and BMI. When we examined the results for the right IJV (RIJV) Dm, the regression coefficient indicated that the 1 year age increase was associated with an increase in the RIJV Dm of $0.414 \mathrm{~mm}$. It was shown that each $1 \mathrm{~kg}$ increase in weyight was associated with an increase of $0.169 \mathrm{~mm}$ in RIJV Dm. Our results also showed that the DM of RIJV increased by $0.073 \mathrm{~mm}$ for every $1 \mathrm{~cm}$ increase in height (Table 5).

Multiple linear regressions of the RIJVs-left IJVs, the most used vessels for central venous catheter administration, and right-left FAs, which were frequently used in arterial catheterization, were performed.

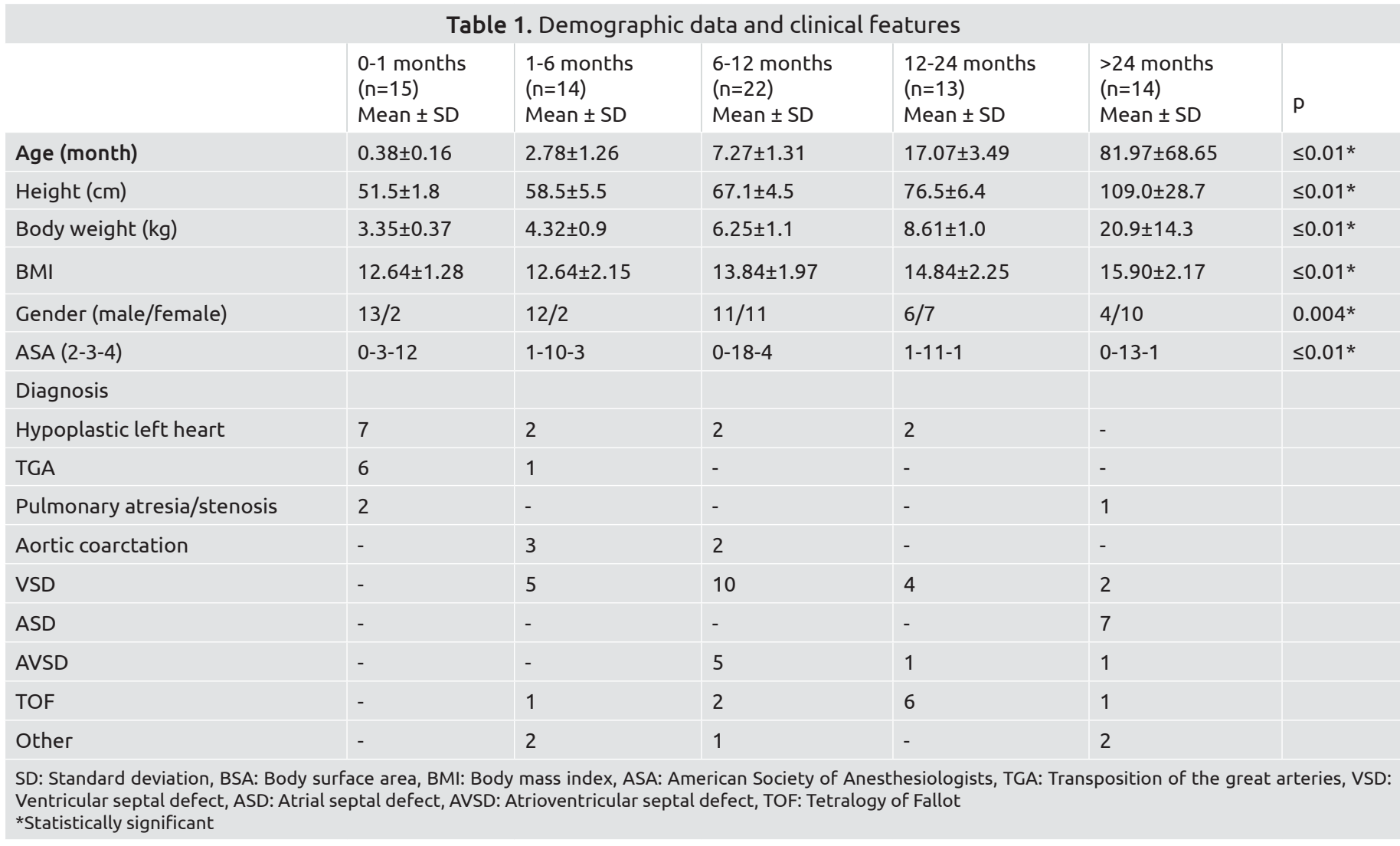


Table 2. Major vein/artery diameters and distance to the skin by group

\begin{tabular}{|c|c|c|c|c|c|}
\hline $\begin{array}{l}0-1 \text { months } \\
(n=15) \\
\text { Mean (SD) }\end{array}$ & $\begin{array}{l}1-6 \text { months } \\
(n=14) \\
\text { Mean (SD) }\end{array}$ & $\begin{array}{l}6-12 \text { months } \\
(n=22) \\
\text { Mean (SD) }\end{array}$ & $\begin{array}{l}12-24 \text { months } \\
(n=13) \\
\text { Mean (SD) }\end{array}$ & $\begin{array}{l}>24 \text { months } \\
(n=14) \\
\text { Mean (SD) }\end{array}$ & $P$ \\
\hline $4.03(0.55)$ & $3.95(0.84)$ & $5.81(0.97)$ & $5.93(1.28)$ & $9.00(1.47)$ & $>.001 *$ \\
\hline $2.78(0.37)$ & $3.16(0.60)$ & $3.85(0.57)$ & $4.57(0.86)$ & $6.10(1.21)$ & $>.001$ * \\
\hline $5.10(1.10)$ & $5.70(1.63)$ & $6.61(0.96)$ & $6.73(1.48)$ & $8.35(1.56)$ & $>.001$ * \\
\hline $3.46(0.58)$ & $4.13(1.01)$ & $5.85(0.95)$ & $6.16(1.82)$ & $8.50(1.57)$ & $>.001$ * \\
\hline $2.78(0.64)$ & $2.90(0.71)$ & $3.63(0.49)$ & $4.43(0.87)$ & $6.00(1.08)$ & $>.001 *$ \\
\hline $5.00(1.60)$ & $5.42(1.41)$ & $6.66(1.06)$ & $6.03(1.71)$ & $8.17(1.75)$ & $>.001 *$ \\
\hline $2.40(0.44)$ & $2.74(0.79)$ & $3.06(0.47)$ & $3.54(0.93)$ & $5.58(0.85)$ & $>.001 *$ \\
\hline $1.82(0.34)$ & $2.00(0.26)$ & $2.07(0.26)$ & $2.90(0.60)$ & $4.73(1.07)$ & $>.001$ * \\
\hline $3.90(1.69)$ & $4.92(2.22)$ & $4.90(2.59)$ & $4.67(1.36)$ & $7.54(2.77)$ & $.001 *$ \\
\hline $2.55(0.64)$ & $2.45(0.73)$ & $3.05(0.53)$ & $3.66(0.93)$ & $5.47(0.86)$ & $>.001$ * \\
\hline $1.71(0.22)$ & $1.94(0.36)$ & $2.13(0.34)$ & $2.70(0.51)$ & $4.72(0.99)$ & $>.001 *$ \\
\hline $3.42(1.33)$ & $4.80(2.74)$ & $4.88(2.47)$ & $4.66(1.03)$ & $7.48(2.72)$ & $>.001$ * \\
\hline
\end{tabular}

SD: Standard deviation, RIJV: Right internal jugular vein, RCA: Right carotid artery, LIJV: Left internal jugular vein, LCA: Left carotid artery, RFV: Right femoral vein, RFA: Right femoral artery, LFV: Left femoral vein, LFA: Left femoral artery, Dm: Diameter, Dp: Depth

*Statistically significant

Table 3. Anatomical variations between groups

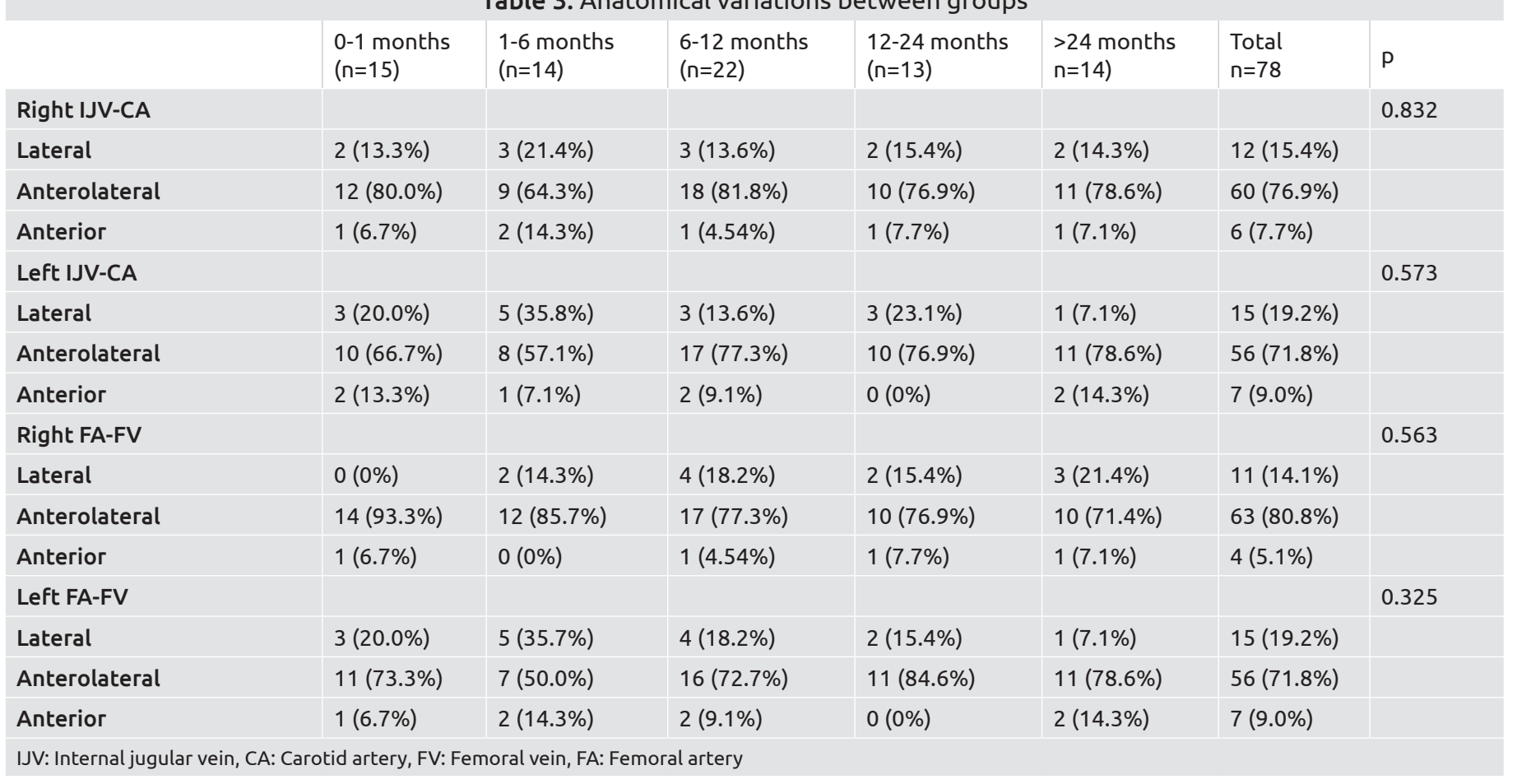

\section{Multiple linear regression RIJV Dm:}

$y=0.159 \times \mathrm{BMI}+0.01 \times$ age $+2,920$

$\mathrm{R}^{2}=0.490 ; \mathrm{p}[\mathrm{BMI}]=0.066 ; \mathrm{p}$ [age] $\leq 0.01$

\section{Multiple linear regression LIJV Dm:}

$\mathrm{y}=0.178 \mathrm{xBM}+0.01 \mathrm{x}$ age $+2,627$

$\mathrm{R}^{2}=0.372 ; \mathrm{p}[\mathrm{BMI}]=0.068 ; \mathrm{p}$ [age $\leq 0.01$

\section{Multiple linear regression RFA Dm:}

$\mathrm{y}=0.040 \mathrm{x} \mathrm{BMI}+0.01 \times$ age $+1,620$
$\mathrm{R}^{2}=0.657 ; \mathrm{p}[\mathrm{BMI}]=0.326 ; \mathrm{p}$ [age] $\leq 0.01$

Multiple linear regression LFA Dm:

$\mathrm{y}=0.061 \times \mathrm{BMI}+0.01 \times$ age $+1,286$

$\mathrm{R}^{2}=0.667 ; \mathrm{p}[\mathrm{BMI}]=0.127 ; \mathrm{p}$ [age $\leq 0.01$

\section{Discussion}

The results of this study provide important information for the treatment of pediatric CVS patients who are likely to have various vascular anatomical variations, as they provide 
Table 4. Correlations between RIJV, LIJV, RCA, LCA, RFV,

RFA, LFV, and LFA diameters, and depths and age, weight, height, BSA, and BMI ( $r$ )

\begin{tabular}{|l|l|l|l|l|l|}
\hline & $\begin{array}{l}\text { Age } \\
\text { (year) }\end{array}$ & $\begin{array}{l}\text { Height } \\
(\mathrm{cm})\end{array}$ & $\begin{array}{l}\text { Weight } \\
(\mathrm{kg})\end{array}$ & $\begin{array}{l}\text { BSA } \\
\left(\mathrm{m}^{2}\right)\end{array}$ & BMI \\
\hline RIJV Dm (mm) & $0.683^{*}$ & $0.823^{*}$ & $0.708^{*}$ & $0.775^{*}$ & $0.478^{*}$ \\
\hline RCA Dm (mm) & $0.738^{*}$ & $0.860^{*}$ & $0.755^{*}$ & $0.815^{*}$ & $0.464^{*}$ \\
\hline RIJV Dp (mm) & $0.546^{*}$ & $0.655^{*}$ & $0.575^{*}$ & $0.622^{*}$ & $0.338^{*}$ \\
\hline LIJV Dm (mm) & $0.585^{*}$ & $0.724^{*}$ & $0.592^{*}$ & $0.667^{*}$ & $0.442^{*}$ \\
\hline LCA Dm (mm) & $0.715^{*}$ & $0.813^{*}$ & $0.724^{*}$ & $0.780^{*}$ & $0.501^{*}$ \\
\hline LIJV Dp (mm) & $0.503^{*}$ & $0.563^{*}$ & $0.506^{*}$ & $0.546^{*}$ & $0.365^{*}$ \\
\hline RFV Dm (mm) & $0.718^{*}$ & $0.810^{*}$ & $0.727^{*}$ & $0.783^{*}$ & $0.479 *$ \\
\hline RFA Dm (mm) & $0.808^{*}$ & $0.881^{*}$ & $0.797^{*}$ & $0.850^{*}$ & $0.466^{*}$ \\
\hline RFA Dp (mm) & $0.420^{*}$ & $0.448^{*}$ & $0.385^{*}$ & $0.424^{*}$ & 0.201 \\
\hline LFV Dm (mm) & $0.702^{*}$ & $0.803^{*}$ & $0.715^{*}$ & $0.770^{*}$ & $0.453^{*}$ \\
\hline LFA Dm (mm) & $0.810^{*}$ & $0.897^{*}$ & $0.819^{*}$ & $0.870^{*}$ & $0.498^{*}$ \\
\hline LFA Dp (mm) & $0.453^{*}$ & $0.504^{*}$ & $0.425^{*}$ & $0.469^{*}$ & 0.187 \\
\hline
\end{tabular}

BSA: Body surface area, BMI: Body mass index, RIJV: Right internal jugular vein, RCA: Right carotid artery, LIJV: Left internal jugular vein, LCA: Left carotid artery: RFV: Right femoral vein, RFA: Right femoral artery, LFV: Left femoral vein, LFA: Left femoral artery, Dm: Diameter, Dp: Depth

*Statistically significant

clinical practice guidance for the anatomical examination of the vessels to be performed before CVC and/or FA catheter administration with USG. At the same time, this study examines the correlation-regression relationship between age, height, weight, BSA, and BMI and major vessels and provides an idea to clinicians on appropriate vessel selection and catheter size during catheterization.

\section{Internal Jugular Vein-carotid Artery}

Barone et al. (9) measured IJVs of 100 newborns undergoing noncardiac surgery and found a strong correlation between the IJV Dm and body weight. Alderson et al. (15) evaluated 50 children younger than 6 years undergoing cardiac surgery and found a strong correlation between IJV Dp and age and body weight; they reported a weak correlation between IJV Dm and age and body weight. Sayin et al. (16), in a study involving 135 patients who had undergone noncardiac surgery, reported a weak correlation of IJV Dm and Dp with age, height, and weight. In our study, we determined that the mean Dm of the IJV varied between 3.46 and $9.00 \mathrm{~mm}$ and its Dp between 5.10 and 8.35 $\mathrm{mm}$; the Dm of the CA was found to vary between 2.78 and $6.10 \mathrm{~mm}$. A high or very high correlation was detected between the Dms of bilateral IJVs and CAs and age, height, weight, and BSA, whereas a moderate correlation was detected with BMI. The strongest correlation was found between vessel $\mathrm{Dm}$ and height. There was a moderate or high correlation between IJV Dp and age, height, weight, and BSA and a weak correlation with BMI. Therefore, we realized that the calculation of vessel $\mathrm{Dm}$ and Dp with BMI in children with congenital heart disease might not provide accurate results.

There was no significant difference between the Dms of right and left IJVs and between the Dms of right and left CAs in our study. This result was parallel with the findings of Karazincir et al. (13), who found similar results between the Dms of right and left IJVs in healthy children aged 0-6 years. In their study evaluating healthy children aged 7-12 years, Yildirim et al. (17) reported that the RIJV Dm was larger than the LIJV Dm.

Vascular malformations and variations may be more common in children with congenital heart disease. This can lead to accidental risk of arterial puncture and many complications. In the healthy population, IJV is the most common anterolateral

\begin{tabular}{|c|c|c|c|c|c|c|c|c|c|c|}
\hline \multicolumn{11}{|c|}{ Table 5. Linear regression models } \\
\hline & $\mathrm{R} 2$ & Coefficient & $\mathrm{R} 2$ & Coefficient & $\mathrm{R} 2$ & Coefficient & $\mathrm{R} 2$ & Coefficient & $\mathrm{R} 2$ & Coefficient \\
\hline RIJV Dm (mm) & 0.466 & 0.414 & 0.678 & 0.073 & 0.501 & 0.169 & 0.601 & 6.410 & 0.228 & 0.426 \\
\hline RCA Dm (mm) & 0.545 & 0.297 & 0.740 & 0.050 & 0.570 & 0.119 & 0.665 & 4.473 & 0.215 & 0.275 \\
\hline RIJV Dp (mm) & 0.299 & 0.273 & 0.428 & 0.048 & 0.330 & 0.113 & 0.386 & 4.238 & 0.114 & 0.249 \\
\hline LCA Dm (mm) & 0.511 & 0.289 & 0.661 & 0.048 & 0.524 & 0.115 & 0.608 & 4.296 & 0.251 & 0.298 \\
\hline LIJV Dp (mm) & 0.253 & 0.270 & 0.317 & 0.044 & 0.256 & 0.106 & 0.298 & 3.992 & 0.133 & 0.288 \\
\hline RFV Dm (mm) & 0.516 & 0.274 & 0.656 & 0.045 & 0.529 & 0.109 & 0.613 & 4.068 & 0.229 & 0.268 \\
\hline RFA Dm (mm) & 0.652 & 0.285 & 0.777 & 0.045 & 0.636 & 0.110 & 0.723 & 4.093 & 0.217 & 0.242 \\
\hline LFA Dp (mm) & 0.205 & 0.339 & 0.254 & 0.055 & 0.181 & 0.125 & 0.220 & 4.780 & 0.035 & 0.206 \\
\hline
\end{tabular}

BSA: Body surface area, BMI: Body mass index, RIJV: Right internal jugular vein, RCA: Right carotid artery, LIJV: Left internal jugular vein, LCA: Left carotid artery, RFV: Right femoral vein, RFA: right femoral artery, LFV: Left femoral vein, LFA: Left femoral artery, Dm: Diameter, Dp: Depth 
location compared with CA (18). However, variations that will complicate catheter interventions may be more frequent in children with congenital heart disease. It has been reported in the literature that IJV is in the anterolateral position at a rate of 54.4-87.8\% compared to CA $(18,19)$. Uzumcugil et al. (20) found that in $84 \%$ of neonatal patients weighing less than 4000 $\mathrm{g}$, the IJV was in the lateral position compared with CA. Souza et al. (21) found that there was an anatomical variation between the IJV and CA in $7.7 \%$ of 142 patients they examined. They reported that the highest variation rate was in children between the age of 1 month and 2 years (21). We determined the position of the IJV relative to the CA on the right side as $76.9 \%$ anterolateral. This rate was $71.8 \%$ on the left. In our study, the rate of anatomical variation between the left-side IJV and CA was higher than that of the right side (28.2\% and $23.1 \%)$. The anatomical variation rate on the left side in the newborn group and in the 1- to 6-month age group was more pronounced than the right side. We found that the most common variation type was IJV located lateral to CA.

\section{Femoral Artery/Vein}

Keiler et al. (22) found that the FV Dm in adults was strongly correlated with gender, age, weight, and BMI but did not correlate with height. López Álvarez et al. (23) found that there was a significant correlation between FA and FV Dm and age, height, weight, and BSA in pediatric patients followed up for non-cardiac reasons, and the highest correlation was found with height. In addition, they reported that there was a significant correlation between FA and FV Dp and age, height, weight, and BSA, but the highest correlation was with weight. In our study, the average FV Dm was between 2.40 and $5.58 \mathrm{~mm}$; we determined that the average FA Dm ranged between 1.71 and $4.73 \mathrm{~mm}$, and the average FA Dp ranged between 3.42 and $7.54 \mathrm{~mm}$. A high or very high correlation was found between the Dms of bilateral FVs and FAs and age, height, weight, and BSA, and a moderate correlation with BMI was detected. The strongest correlation was seen between vessel $\mathrm{Dm}$ and height. There was a moderate correlation between the Dp of FA and age, height, weight, and BSA and a weak correlation with BMI. Our correlation results between FV and FA Dm and age, height, weight, and BSA were in line with previous studies. Therefore, we concluded that the calculation of the FV-FA Dm and FA Dp with BMI might not provide accurate results in children with congenital heart disease.

In our study, we found no significant difference between the Dm of right and left FVs or between the Dm of right and left FAs. This result was similar to the study of Keiler et al. (22), who detected significant bilateral asymmetry between the Dm of right and left FVs. However, in our study, the FV Dm was larger on both sides than the FA Dm in all age groups.

In their study of pediatric patients, Souza et al. (21) stated that there was an anatomic variation of $9.8 \%$ between FA and FV and this was most common in children between 1 month and 2 years of age (24.4\%). They also reported that the most common variation type was FA with anterolateral location to FV (21). Warkentine et al. (2) stated that FA was $88 \%$ laterally located compared with FV. We determined the anterolateral position of FA according to FV on the right side in $80.8 \%$ of the patients. This rate was $71.8 \%$ on the left. The variation between the FA and FV on the left was greater than on the right $(28.2 \%$ and $19.2 \%$ ). We determined that the most common variation type was FV located medial to FA.

\section{Effects on Clinical Practice}

The relationship between vessel Dm and catheter size in terms of development of thrombosis is well known. Therefore, studies have reported that the ideal catheter Dm is approximately onethird of the vessel Dm $(9,20)$. Based on the data from our study, for IJV cannulation, 3 French $(1 \mathrm{~mm})$ catheters can be used in newborns, 3-4 French $(1 \mathrm{~mm})$ in children aged 1-6 months, 4-5 French (1.3-1.6 mm) for children 6-12 months, 5-6 French (1.6-2.0 mm) for children 12-24 months, and 5-7 (1.6-2.4 mm) French for children $>24$ months. For FA cannulation, 2 French catheters can be used for newborns, 2 French for children aged 1-6 months, 2 French for children 6-12 months, 2-3 French for children 12-24 months, and 3 French for children $>24$ months. However, instead of estimating, it would be more accurate to determine the catheter Dm by measuring with USG by experienced people.

\section{Study Limitations}

1. Because USG evaluation is subjective and depends on clinical experience, measurements using computed tomography or angiography can provide more accurate results in children with congenital heart disease. To minimize this error, two anesthesiologists with at least 5 years of clinical USG experience and experience in pediatric cardiac surgery performed all measurements.

2. We did not measure the SV used in central venous catheter administrations.

3. Only the anterior and posterior Dms of the vessels were measured. The transverse Dm or cross-sectional area of the vessel was not measured. Long-axis anatomical evaluations of the vessels were absent in our study.

4. The investigation was made with the patient only in the supine position. No measurement was made in the Trendelenburg position, which could lead to a change in vessel $\mathrm{Dm}$.

5. The Dms and anatomic variations of femoral vessels were not evaluated according to some leg positions.

6. Measurements were made with patients on mechanical ventilation. Therefore, the extent to which mechanical ventilation affected vessel $\mathrm{Dm}$ could not be evaluated.

7. Due to the low number of patients, we could not make a separate formulation that would determine the vessel Dm in all age groups. This may be the subject of larger series studies. 


\section{Conclusion}

In this study, we found a high correlation between vascular Dms and age, weight, height, and BSA in children with congenital heart disease. However, we believe that determining the vessel Dm with BMI in children with congenital heart disease may not lead to the correct result. We found an anatomical variation rate of $28.2 \%$ on the left and $23.1 \%$ on the right between IJV and CA. We found that the most common variation type was IJV located lateral to CA. We established that the rate of anatomical variation between FA and FV was $28.2 \%$ on the left and $19.2 \%$ on the right.

Our study provides important data for clinicians in terms of USG evaluation for appropriate vessel selection, determination of anatomical variations, and determination of catheter size and needle length before catheterization in pediatric patients undergoing cardiac surgery, which is a special patient population. Therefore, the routine use of USG in venous catheter and/or arterial catheter interventions in pediatric patients undergoing cardiac surgery will benefit in terms of increased interference success and reduced complications.

\section{Ethics}

Ethics Committee Approval: This study was approved by the Local Ethics Committee University of Health Sciences Turkey Gazi Yaşargil Training and Research Hospital (approval date and number: 20.12.2019-402).

Informed Consent: Retrospective study

Peer-review: Externally peer reviewed.

\section{Authorship Contributions}

Concept: F.S., Design: F.S., M.B., E.A.B., C.K.K., O.D., Analysis or Interpretation: H.A., S.K., A.E., Writing: F.S., M.B., E.A.B., C.K.K., O.D., H.A., S.K., A.E.

Conflict of Interest: No conflict of interest was declared by the authors.

Financial Disclosure: The authors declared that this study received no financial support.

\section{References}

1. Staudt GE, Eagle SS, Hughes AK, Donahue BS. Evaluation of Dynamic Ultrasound for Arterial Access in Children Undergoing Cardiac Surgery. J Cardiothorac Vasc Anesth 2019;33:1926-29.

2. Warkentine FH, Clyde Pierce M, Lorenz D, Kim IK. The anatomic relationship of femoral vein to femoral artery in euvolemic pediatric patients by ultrasonography: implications for pediatric femoral central venous access. Acad Emerg Med 2008;15:426-30.

3. Álvarez JML, Quevedo OP, Cabrera LS, Escot CR, Lorenzo TR, Cañal JL, et al. Vascular ultrasound in pediatrics: utility and application of location and measurement of jugular and femoral vessels. J Med Ultrason 2018;45:469-77.

4. Shiloh AL, Eisen LA. Ultrasound-guided arterial catheterization: a narrative review. Intensive Care Med 2010;36:214-21.
5. Law MA, Borasino S, McMahon WS, Alten JA. Ultrasoundversus landmark-guided femoral catheterization in the pediatric catheterization laboratory: a randomized-controlled trial. Pediatr Cardiol 2014;35:1246-52.

6. Siddik-Sayyid SM, Aouad MT, Ibrahim MH, Taha SK, Nawfal MF, Tfaili YJ, et al. Femoral arterial cannulation performed by residents: a comparison between ultrasound-guided and palpation technique in infants and children undergoing cardiac surgery. Paediatr Anaesth 2016;26: 823-30.

7. Yıldız Y. Comparison of The Effects of Percutaneous Catheter Insertion with Anatomic Landmark or Ultrasonography Guided Techniques on Hospital Cost in Children.GKDA Derg 2019;25:96-101.

8. Spencer TR, Pittiruti M. Rapid Central Vein Assessment (RaCeVA): A systematic, standardized approach for ultrasound assessment before central venous catheterization. J Vasc Access 2019;20:239-49.

9. Barone G, D'Andrea V, Vento G, Pittiruti M. A Systematic Ultrasound Evaluation of the Diameter of Deep Veins in the Newborn: Results and Implications for Clinical Practice. Neonatology 2019;115:335-40.

10. Hoffman T, Du Plessis M, Prekupec MP, Gielecki J, Zurada A, Tubbs RS, et al. Ultrasound-guided central venous catheterization: A review of the relevant anatomy, technique, complications, and anatomical variations. Clin Anat 2017;30:237-50.

11. Altun D, Nuraç SH, Toprak V, Eti EZ. The success rate and safety of internal jugular vein catheterization under ultrasound guidance in infants undergoing congenital heart surgery. Turk Gogus Kalp Damar Cerrahisi Derg 2019;27:23-8.

12. Yıldız Y, Ulukan MÖ, Cantürk E, Gül YG, Erkanlı K, Demiraran Y, et al. The Comparison of Percutaneous Central Venous Catheter Insertion Methods with the aid of Anatomical Description and Ultrasonographic Guidance - Single Center Experience. GKDA Derg 2019;25:160-6.

13. Karazincir S, Akoğlu E, Balci A, Sangün O, Okuyucu S, Ozbakiş C, et al. Dimensions of internal jugular veins in Turkish children aged between 0 and 6 years in resting state and during Valsalva maneuver. Int J Pediatr Otorhinolaryngol 2007;71:1247-50.

14. Mosteller RD. Simplified calculation of body-surface area. N Engl J Med 1987;317:1098.

15. Alderson PJ, Burrows FA, Stemp LI, Holtby HM. Use of ultrasound to evaluate internal jugular vein anatomy and to facilitate central venous cannulation in paediatric patients. Br J Anaesth 1993;70:145-8.

16. Sayin MM, Mercan A, Koner O, Ture H, Celebi S, Sozubir S, et al. Internal jugular vein diameter in pediatric patients: are the J-shaped guidewire diameters bigger than internal jugular vein? An evaluation with ultrasound. Paediatr Anaesth 2008;18:745-51.

17. Yildirim I, Yüksel M, Okur N, Okur E, Kýliç MA. The sizes of internal jugular veins in Turkish children aged between 7 and 12 years. Int J Pediatr Otorhinolaryngol 2004;68: 1059-62.

18. Turba UC, Uflacker R, Hannegan C, Selby JB. Anatomic relationship of the internal jugular vein and the common carotid artery applied to percutaneous transjugular procedures. Cardiovasc Intervent Radiol 2005;28:303-6. 
19. Roth B, Marciniak B, Engelhardt T, Bissonnette B. Anatomic relationship between the internal jugular vein and the carotid artery in preschool children--an ultrasonographic study. Paediatr Anaesth 2008;18:752-6.

20. Uzumcugil F, Yilbas AA, Akca B. Ultrasound-guided anatomical evaluation and percutaneous cannulation of the right internal jugular vein in infants <4000 g. J Vasc Access 2020;21:92-7.

21. Souza P, Neto E, Grousson S, Duflo F, Tahon F, Mottolese C, Dailler F. Ultrasonographic anatomic variations of the major veins in paediatric patients. Br J Anaesth 2014;112: 879-84.
22. Keiler J, Seidel R, Wree A. The femoral vein diameter and its correlation with sex, age and body mass index - An anatomical parameter with clinical relevance. Phlebology 2019;34:58-69.

23. López Álvarez JM, Pérez Quevedo O, Santana Cabrera L, Escot CR, Ferrer JL, Lorenzo TR, et al. Vascular ultrasound in pediatrics: estimation of depth and diameter of jugular and femoral vessels. J Ultrasound 2017;20:285-92. 